\title{
DISPLASIA FIBROSA DO OSSO TEMPORAL E VASCULOPATIA OCLUSIVA CEREBRAL
}

\author{
RELATO DE CASO
}

\author{
ELAINE INAMORATO*-ROBERTO GOMES NOGUEIRA ** \\ SUSANMEIRE N. MINATTI-HANNUCH *** - ELIOVA ZUKERMAN****
}

\begin{abstract}
RESUMO - Displasia fibrosa é doença óssea benigna de etiologia desconhecida. o envolvimento craniofacial pode causar distúrbios neurológicos. O diagnóstico é feito pelo aspecto radiográfico. E apresentado un caso de associação entre quadro clínico de displasia fibrosa, com envolvimento do nervo facial, infartos cerebrais e título elevado de anticorpo anticardiolipina. A angiografia mostrou oclusões de várias artérias cerebrais. O exame pós-morte revelou infarto recente do miocárdio, amolecimento cerebral isquêmico e arteriosclerose generalizada.
\end{abstract}

PALAVRAS-CHAVE: displasia fibrosa, trombose cerebral, anticorpo anticardiolipina.

Fibrous dysplasia of the temporal bone and cerebral occlusive vasculopathy : case report.

SUMMARY - Fibrous dysplasia is a benign disease with unknown etiology. Skull attempt may cause neurological disorders. The diagnostic can be made through radiological examination. A case of a patient with right temporal bone involvement with facial palsy, right parietal lobe infarctions and elevated anticardiolipin antibody titers is presented. Cerebral angiography showed occlusion of several cerebral arteries. Post mortem examination displayed recent myocardial infarction, ischemic cerebral softening, and generalized arteriosclerosis. The simultaneous occurrence of fibrous dysplasia and a probable anticardiolipin syndrome is commented.

KEY WORDS: fibrous dysplasia, cerebral thrombosis, anticardiolipin antibody.

A displasia fibrosa (DF), descrita em 1891 por von Recklinghausen, é doença progressiva, benigna e de etiologia desconhecida, na qual há substituição do tecido esponjoso da medula óssea por tecido fibroso anormal, formado por metaplasia óssea e que contém trabéculas de osso primitivo pouco calcificadas, justificando o nome proposto por Lichtenstein em 19382,14 . A DF se apresenta nas formas monostótica (a mais frequente), poliostótica sem endocrinopatia e poliostótica com endocrinopatia (a mais rara), sendo então chamada de síndrome McCune-Albright. O acometimento ocorre durante o crescimento ósseo, sendo ao redor de 14 anos, habitualmente, na forma monostótica, dos 11 anos na poliostótica sem endocrinopatia e dos 8 anos na poliostótica com endocrinopatia 14,16.

A oportunidade de examinar um paciente com DF no qual se verificou título sérico elevado de anticorpo anticardiolipina motivou o presente registro.

Setor de Investigação e Tratamento das Cefaléias (SITC) do Departiamento de Neurologia e Neurocirurgia (1) e Departamento de Diagnóstico por Imagem (2) da Escola Paulista de Medicina: * Pós-graduanda (1); ** Professor Assistente de Neurorradiologia (2); *** Doutor em Medicina e Médica Assistente (1); **** Professor Adjunto e Chefe do SITC (1).

Dr. Eliova Zukerman - Disciplina de Neurologia, Escola Paulista de Medicina - Rua Botucatu 740 - 04023 São Paulo SP - Brasil. 


\section{OBSERVAÇÄO}

ARS, paciente do sexo masculino, com 39 anos de idade, acometido subitamente de paralisia facial periférica direita há 7 dias e hemiparesia completa desproporcionada de predomínio braquial no dimídio esquerdo, além de hemi-hipoestesia de mesma localização. Após 5 dias novo icto, com piora do déficit motor, mais acentuado no membro superior esquerdo. Este déficit permaneceu inalterado até o quinto mês após o icto, quando ocorreu a óbito. Foram realizados os seguintes exames - Hemograma: eritrócitos 5000000/mm3; hemoglobina 14.5g/dl; hematócrito 45\%; glóbulos brancos $6100 / \mathrm{mm} 3$, com diferencial normal; plaquetas 408000/mm3. VHS: 40mm na primeira hora. 'Fosfatase alcalina: 189/UL. Cálcio: 9,4mg/dl; Fósforo: 4,2mg/dl. Eletroforese de proteínas séricas (em $\mathrm{g} / \mathrm{dl}$ ): albumina 3,65; alfa-1: 0,17 ; alfa2: 0,66 ; beta: 1,16; gama: 2,66; proteinas totais: 8,30 . Proteina de Bence Jones: negativa. Colesterol total $245 \mathrm{mg} / \mathrm{dl}$; HDL $33 \mathrm{mg} / \mathrm{dl}$; LDL $187 \mathrm{mg} / \mathrm{dl}$. Urina tipo 1 normal. Reacāo para anticorpo anticardiolipina positiva (1/640). FAN negativo; CH50: 252U. RX do crânio: aumento da densidade e espessura do osso temporal direito. Estudo radiológico do esqueleto; normal. Tomografia computadorizada de crânio (Fig. 1): mostrou as alterações observadas no $\mathrm{RX}$ de crânio e áreas isquêmicas nas regiōes fronto-parietal e temporal direitas. Angiografia cerebral (Fig. 2): oclusão total da artéria carótida interna direita no nível da bifurcação, oclusão parcial na origem da artéria cerebral anterior esquerda e opacificação das artérias cerebrais anteriores através de anastomoses pericalosas com o sistema vértebro basilar. Biópsia do osso temporal (efetuada na ocasião em que foi feita a descompressão do osso temporal) revelou cortical óssea normal e material necrótico, não sendo conclusiva. A verificação de óbito, realizada no Instituto Médico Legal, mostrou infarto agudo do miocárdio, amolecimento cerebral isquêmico e arteriosclerose generalizada.

\section{COMENTÃRIOS}

DF é a mais frequente das doenças esqueléticas benignas que acometem o crânio 16. O envolvimento craniofacial ocorre em $10 \%$ na forma monostótica, variando de 50 a $100 \%$ nas formas poliostóticas. Os ossos frontal e esfenoidal são mais fre-

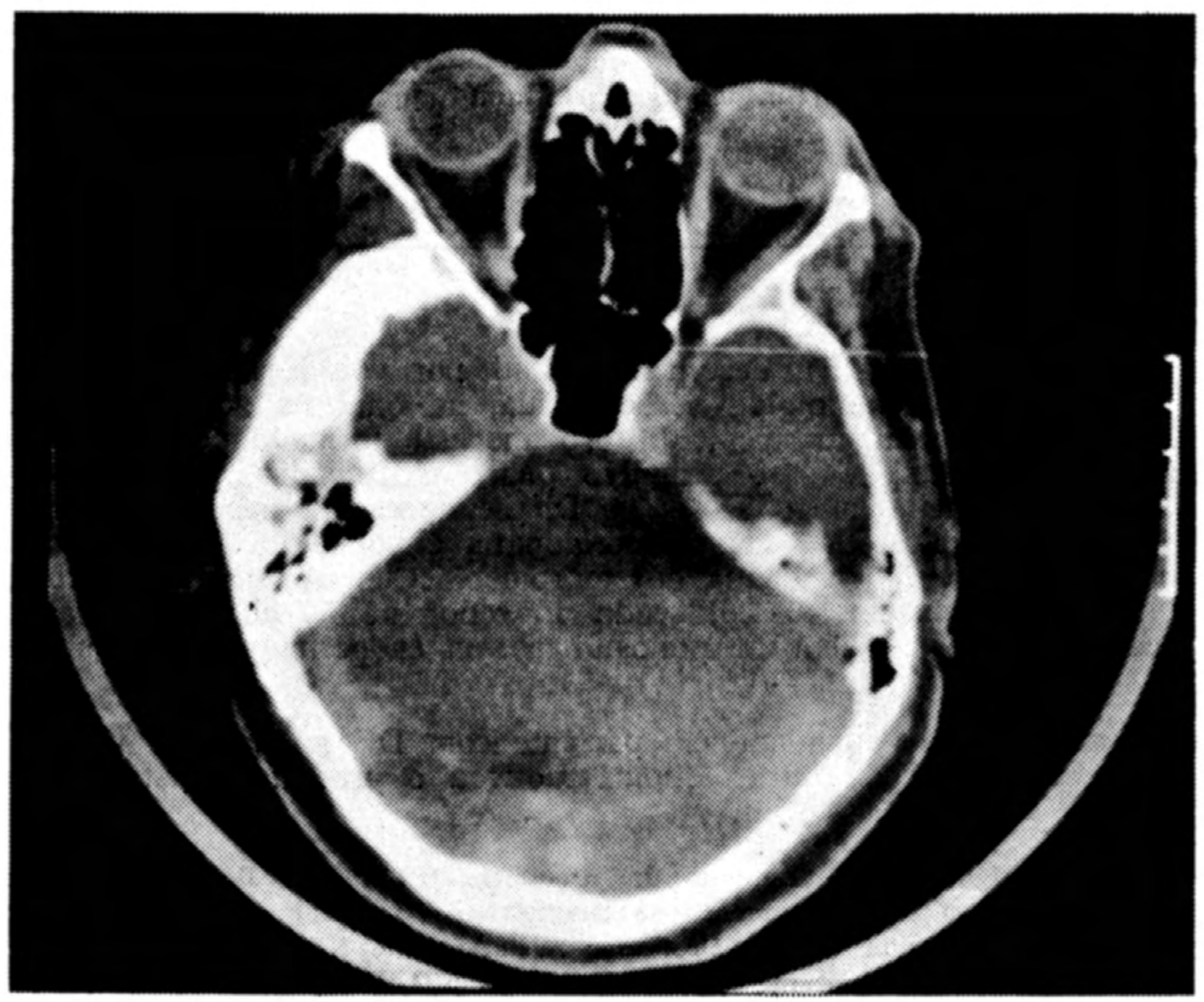

Fig. 1. Tomografia computadorizada de cranio (janela óssea) mostrando osso temporal direito. 


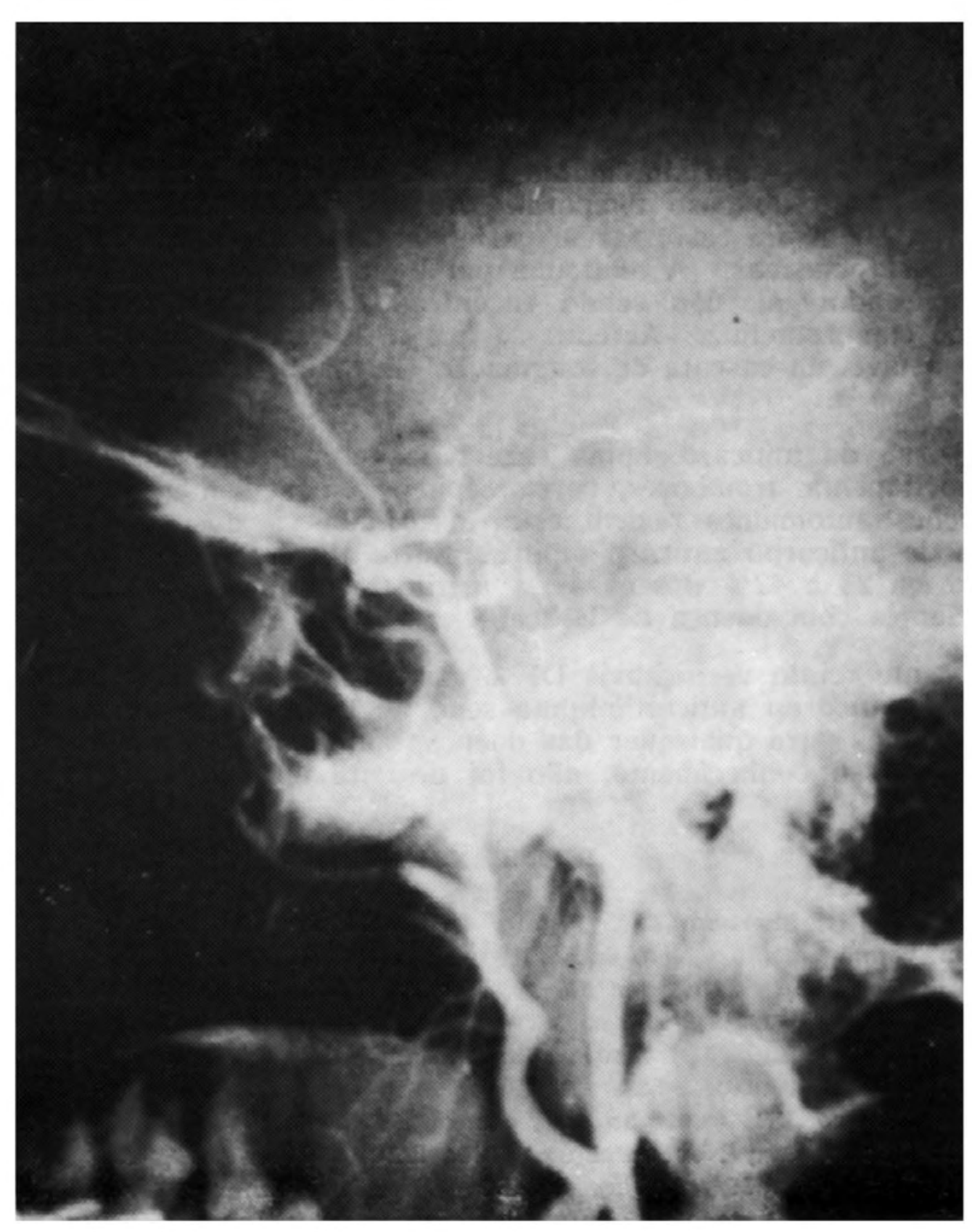

Fig. 2. Angiografia cerebral mostrando obstrucdo da artéria carotida interna direita. Observar arteria carbtida intrapetrosa normal.

quentemente afetados. Os ossos temporais são afetados em cerca de $18 \%$ dos casos 14,16. Conforme o grau de envolvimento, pode haver deslocamento do globo ocular, compressão do nervo óptico e comprometimento do nervo olfatório, causando distúrbios visuais, hiposmia ou anosmia. O envolvimento do osso temporal pode causar «tinnitus», hipoacusia neurossensorial progressiva, distúrbios da função vestibular e paralisia facial periférica 4,14 .

O diagnóstico da DF é feito pelo exame radiológico convencional 12. Nos pacientes com sintomas neurológicos, o estudo rádiológico deve compreender todo o esqueleto, mesmo na ausência de outras manifestações clínicas, pois são comuns as formas poliostóticas assintomáticas 4. A angiografia cerebral pode ser indicada para o diagnóstico diferencial com meningeoma $\mathrm{cm}$ placa 11 ; na DF as alteraçĩes angiográficas são exclusivamente extracranianas, sendo possivel a ocorrência de dilatação da artéria temporal superficial e seus ramos, presença de pequenos vasos anormais extracranianos, opacificação precoce de grandes veias e aneurismas arteriais e venosos extracranianos 11. Alguns autores acreditam que, na forma monostótica, o diagnóstico deve ser confirmado por biópsia 13,14. Entretanto, Freire e col. a indicam apenas em casos excepcionais 4.

No presente relato, optamos pela realização de biópsia, o que, entretanto, não acrescentou dados ao diagnóstico. A repetição deste procedimento não foi possível devido ao óbito. 
A cirurgia está indicada nos casos em que ocorre compressão de nervos ou alterações estéticas importantes. Cerca de metade dos pacientes cirúrgicos necessita de duas ou mais intervenções. As compressões recidivam em cerca de $25 \%$ dos casos 15 .

O caso por nós relatado é compatível à forma monostótica de DF e o acometimento do nervo facial, cuja sintomatologia deu início ao quadro clínico, é explicado pelo comprometimento do osso temporal. As alterações vasculares encontradas não são descritas na DF e, no caso, fazem parte da sindrome da anticardiolipina, na qual existem alterações oclusivas. A anatomia patológica mostra a parede do vaso normal ou com edema endotelial, não sendo encontrados infiltrados celulares próximos do vaso na região comprometida. Acredita-se que a doença vascular oclusiva ocorra por reação imune a nível da cascata de coagulação causando trombose e não por alteração na parede do vaso 10.

A síndrome da anticardiolipina caracteriza-se pela presença de abortos recorrentes, trombocitopenia, tromboses, coréia, epilepsia e acidente vascular cerebral 1,5-9. Outras condições autoimunes podem estar associadas à doença vascular oclusiva e elevado título de anticorpo anticardiolipina. Entre elas encontram-se o lupus eritematoso sistêmico em 23 a $42 \%$ dos casos, a artrite reumatóide $\mathrm{cm} 33 \%$ dos casos e em $28 \%$ dos pacientes com doença de Behçet 3 .

No presente relato verificamos DF e vasculopatia arterial oclusiva com elevado título sérico de anticorpo anticardiolipina sem, no entanto, preencher os critérios clínicos e laboratoriais para quaisquer das doenças autoimunes citadas. Esta associação, até onde é do nosso conhecimento, não foi descrita na literatura.

\section{REFERENCIAS}

1. Brey RL, Hiart RG, Sherman DG, Tegeler CH. Antiphospholipid antibodies and cereinral isquemia in young people. Neurology 1990, 40:1190-1195.

2. Daffner RH, Kirko DR, Gehweiler JA Jr, Heaston DK. Computed tomography of fibrous dysplasia. AJR 1982, 139:943-948.

3. Damao-Camara T, Clough JD. Anticardiolipin antibodies in systemic lupus eritematosus. Clev Clin J Med 1989, 56:525-528.

4. Freitas PE, Ribeiro TR, Coutinho MF, Anicet A. Displasia fibrosa do crânio: manifestações neurológicas. Arq Neuro-Psiquiat (São Paulo) 1989, 47:187-191.

5. Hamsten A, Bjorkholm $M$, Norberg $R$, De Faire V, Holm G. Antibodies to cardiolipin in young survivors of myocardial infarction: an association with recurrent cardiovascular events. Lancet 1986, 2:113-115.

6. Hughes GRV. The anticardiolipin syndrome. J Rheumatol 1986, 13:486-489.

7. Levine SR, Deegan MJ, Futrell N, Welch KMA. Cerebrovascular and neurologic disease associated with antiphospholipid antibodies: 48 cases. Neurology 1990, 40:1181-1189.

8. Levine SR, Kim S, Deegan MJ, Welch KMA. Ischemio stroke associated with anticardiolipin antibodies. Stroke 1987, 18:1101-1106.

9. Levine SR, Welch KMA. The spectrum of neurologic disease associated with anticardiolipin antibodies: lupus eritematosus anticoagulants and anticardiolipin antibodies. Arch Neurol 1987, 44:876-883.

10. Levine SR, Welch KMA. Antiphospholipid antibodies. Ann Neurol 1989, 26:386-389.

11. Lin JP, Goodkin R, Chase NE, Kricheff II. The angiographic features of fibrous dysplasia of skull. Radiology 1969, $92: 1275-1280$.

12. Mendelson DB, Hetzanu J, Cohen M, Tello G. Computed tomography of craniofacial fibrous dysplasia. J Comput Assist Tomogr 1984, 8:1062-1065.

13. Nager GT, Holliday MJ. Fibrous dysplasia of the temporal bone: Update with case reports. Ann Otol Rhinol Laryngol 1984, 93:530-633.

14. Nager GT, Kennedy DW, Kopstein E. Fibrous dysplasia: a review of the disease and manifestations in the temporal bone. Ann Otol Rhinol Laringol 1982, 91 (suppl 92):1-52.

15. Ramsey HE, Strong EW, Frazel EL. Fibrous dysplasia of the craniofacial bones. Am J Surg 1968, 116:542-547.

16. Younus M, Haleen A. Monostotic fibrous dysplasia of the temporal bone. J Laryngol Otol 1987, 101:1070-1074. 